\title{
Effect of Skipping Breakfast on Young Girls’ Menstruation
}

\author{
Angelin Priya ${ }^{1}$, Dileep Dandotiya ${ }^{2}$, Manju Toppo ${ }^{3}$, Veena Melwani ${ }^{4}$, \\ Pradeep Dohare $^{5}$, Amreen Khan ${ }^{6}$, Soumitra Sethia ${ }^{7}$
}

\begin{abstract}
Introduction: Breakfast is often referred to as the most important meal of the day. Evidence suggests that breakfast contributes to wellbeing in a number of areas. First, it is a central component of nutritional wellbeing, contributing to total daily energy and nutrient intake. Nearly $15 \%$ of college girls rarely or never ate breakfast, and those who ate breakfast almost every day (and did not often eat between meals) reported slightly but significantly better physical health than skippers. Eating breakfast is important for the health and development of young women. From clinical experience, there is great evidence that the frequency of irregular menstruation and intensity of dysmenorrhea was increased in young women, who were currently skipping meals, suggesting that diet in adolescence has long-lasting adverse effects on reproductive function in young women. Menstrual disorders frequently affect the quality of life of adolescents and young adult women. Breakfast as a part of healthful diet and lifestyle can positively impact children's and young adults' health and wellbeing. Daily eating habits significantly influence menstrual function in young women. We conducted the study to explore the association of skipping breakfast on menstruation.
\end{abstract}

Objectives

- To find out the proportion of girls with menstrual irregularity in those skipping breakfast;

- To find out effect of breakfast skipping on menstruation among girls of age group 17-22 years.

Method and Material: A cross-sectional study was used. The studied sample consisted of 90 female students of a selected college of Bhopal city. Data were collected by using an interviewing questionnaire. Analysis of the findings was done using Epi Info 7 software.

Results: Mean age of the study participants was $20+3.66$ years. Out of 90 students, $82 \%$ were found to have been skipping breakfast for more than 3 days a week. The study also revealed that dysmenorrhea was more in girls who skipped breakfast than in those who had breakfast $(P=0.0001)$.

Conclusion: From the above finding, we can conclude that episodes of dysmenorrhea occurred more in female students who skipped the breakfast meal more than those who took breakfast regularly.

Keywords: Menstruation, Dietary habits, Skipping breakfast, BMI, Premenstrual syndromes, Menstrual disorders

${ }^{13}$ rd Year Post Graduate Student, ${ }^{2,4,5,6} 1$ st Year Post Graduate Student, ${ }^{3}$ Assistant Professor, ${ }^{7}$ 2nd Year Post Graduate Student, Department of Community Medicine, Gandhi Medical College, Bhopal.

Correspondence: Dr. Dileep Dandotiya, Department of Community Medicine, Gandhi Medical College, Bhopal.

E-mail Id: dr.dileep85@gmail.com

Orcid Id: https://orcid.org/0000-0001-8922-7452

How to cite this article: Priya A, Dandotiya D, Toppo M et al. Effect of Skipping Breakfast on Young Girls' Menstruation. Ind J Youth Adol Health 2017; 4(3): 17-20.

Digital Object Identifier (DOI): https://doi.org/10.24321/2349.2880.201720

ISSN: $2349-2880$ 


\section{Introduction}

Breakfast is often referred to as the most important meal of the day. Evidence suggests that breakfast contributes to wellbeing in a number of areas. First, it is a central component of nutritional wellbeing, contributing to total daily energy and nutrient intake. ${ }^{1}$ Daily eating habits significantly influence menstrual function in young women and several studies reported that vitamin deficiency or hypoglycemia can induce premenstrual syndromes in which patients complain of irritability, constipation and edema several days before the onset of menstruation. Very recently, it was confirmed that the frequency of irregular menstruation was increased in young women who were currently on a diet and found out that the intensity of dysmenorrhea was high in those with a history of dieting in adolescence, suggesting that diet in adolescence has longlasting adverse effects on reproductive function in young women. ${ }^{2}$ Menstrual disorders frequently affect the quality of life of adolescents and young adult women. Breakfast as a part of healthful diet and lifestyle can positively impact children's and young adults' health and wellbeing and development of young women. Nearly $15 \%$ of college girls rarely or never ate breakfast, and those who ate breakfast almost every day (and did not often eat between the meals) reported slightly but significantly better physical health than skippers. Irregular menstruation is one of the positive clinical symptoms which predict dysfunction of the hypothalamic-pituitary-ovarian axis. The list of menstrual disorders may range from amenorrhea, irregular cycles and abnormal flow to dysmenorrhea and premenstrual symptoms (Campbell and McGrath, 1997). Dietary habits are fundamental factors that influence human life style and individual quality of life (QOL). Dietary habits in young women may determine their QOL in subsequent middle or old age and should be evaluated from the perspective of total benefit throughout whole life. ${ }^{3-5}$ Meal skipping rates may be highest during young adulthood, a period of transition and development. Although these dietary behaviors may increase future risk of chronic disease, limited research has investigated correlates of meal skipping in young adults; therefore, we conducted the study to explore the association of skipping breakfast on menstruation. .,7 $^{6}$

\section{Objectives}

- To find out the proportion of girls with menstrual irregularity in those skipping breakfast.

- To find out effect of breakfast skipping on menstruation among girls of age group 17-22years.

\section{Methodology}

A total of 90 students in the age group ranging from 17 to 22 were selected for the present study. A cross-sectional study was carried out in a selected girls' college of Bhopal city belonging to 17-22 years of age, after taking consent from the college authorities and approval from our institutional ethical committee. This study was carried out with a questionnaire to collect data on breakfast history, food habits, sleeping habits, physical activities and menstrual cycle and also the all study subjects were briefed and requested to answer the questionnaire. The questionnaire was self-administered, semi-structured and prepared in English language. The obtained data were entered into Microsoft Excel 2007 and analyzed by using Epi info 7.

\section{Results}

Age of the study participants was $20+3.66$ years. Out of 90 students, $82 \%$ were found to have been skipping breakfast for more than 3 days a week. The study also revealed that dysmenorrhea was more in girls who skipped the breakfast than in those who had breakfast ( $P=0.0001)$.

Table 1.Characteristics of Study Participants

\begin{tabular}{|c|c|}
\hline Characteristics & Frequency (\%) \\
\hline Mean age of the study participants & $20 \pm 3.66$ \\
\hline Mean age of menarche & $13.34 \pm 1.39$ \\
\hline \multicolumn{2}{|c|}{ Height } \\
\hline$<150 \mathrm{~cm}$ & $20(22.22)$ \\
\hline $150-160 \mathrm{~cm}$ & $39(43.33)$ \\
\hline$>160 \mathrm{~cm}$ & $31(34.44)$ \\
\hline \multicolumn{2}{|c|}{ Weight } \\
\hline$<50 \mathrm{~kg}$ & $39(43.33)$ \\
\hline$>50 \mathrm{~kg}$ & $51(56.66)$ \\
\hline \multicolumn{2}{|c|}{ BMI } \\
\hline Underweight $(<18.5)$ & $20(22.22)$ \\
\hline Normal (18.5-24.9) & $53(58.88)$ \\
\hline Overweight (>25) & $17(18.88)$ \\
\hline Having breakfast & $16(17.77)$ \\
\hline Skipping breakfast & $74(82)$ \\
\hline
\end{tabular}


Table 2.Dietary Habits and Life Style

\begin{tabular}{|c|c|c|}
\hline Junk Foods & Skipping Breakfast (74) & Having Breakfast (16) \\
\hline$<3$ times per week & 29 & 4 \\
\hline$>3$ times per week & 45 & 7 \\
\hline \multicolumn{2}{|c|}{ Fresh fruits and juices } \\
\hline < days per week & 15 & 9 \\
\hline 4-7 days per week & 59 & 9 \\
\hline <3 days per week & Physical activity & 6 \\
\hline 4-7 days per week & 22 & 1 \\
\hline
\end{tabular}

Table 3.Distribution according to Menstrual History

\begin{tabular}{|c|c|c|}
\hline Characteristics & Having Breakfast(16) & Skipping Breakfast(74) \\
\hline Menstrual duration (in days) & & $44(59.46)$ \\
\hline$<3$ & $5(31.25)$ & $20(27.02)$ \\
\hline $3-7$ & $8(50)$ & $10(13.52)$ \\
\hline$>7$ & $3(18.75)$ & $12(16.02)$ \\
\hline Blood flow & & $62(83.78)$ \\
\hline With clot & $16(100)$ & 0 \\
\hline Without clot & 0 & \\
\hline
\end{tabular}

Table 4.Association between Skipping Breakfast and Menstrual Disorder

\begin{tabular}{|c|c|c|c|c|}
\hline $\begin{array}{c}\text { Menstrual Disorder } \\
\text { Dysmenorrhea }\end{array}$ & Have Breakfast (16) (\%) & Skip Breakfast (74) & Chi-square & P value \\
\hline Yes & $04(25)$ & $60(81.08)$ & 20.1407 & 0.0001 \\
\hline No & $12(75)$ & $14(18.91)$ & & \\
\hline Menorrhagia & $13(81.25)$ & $12(16.22)$ & 14.673 & 0.126 \\
\hline Yes & $03(18.65)$ & $62(83.78)$ & & \\
\hline No & & & & \\
\hline Oligomenorrhea & $01(6.25)$ & $55(74.32)$ & 25.93 & $<0.05$ \\
\hline Yes & $15(93.75)$ & $19(25.67)$ & & \\
\hline No & & & & \\
\end{tabular}

\section{Discussion}

Our study found out that majority of study participants skipping breakfast were suffering from one or the other menstrual problems. This finding is consistent with the finding of study done by Hayam Fathy A. Eittah on 300 girls of nursing in Menoufiya University, Egypt. ${ }^{2}$

In addition, Dars et al., in their study on female students in Hyderabad, Pakistan, ${ }^{8}$ showed a significant association between nutritional status and menstruation pattern, which is found in our study as well.

\section{Conclusions}

Based on the study, finding episodes of menstrual disorder was more in those who skipped breakfast than who regularly had breakfast. The current study revealed that dysmenorrhea and oligomenorrhea occurs in female students who skipped the breakfast meal more than those who took breakfast.

\section{Recommendation}

Encouragement should be done to take healthy breakfast to all female students studying in schools and colleges. Evaluation of breakfast skipping should be carried out in perspective of future reproductive functions. This problem needs to be examined with a larger sample size. Development of educational programs to increase awareness about the importance and effect of breakfast on target girls from different ages should be done.

Conflict of Interest: None

\section{References}

1. Shaw, Mary E. Adolescent breakfast skipping: An Australian study. Adolescence Winter 1998; 33(132): 851-61.

2. Hayam Fathy A. Eittah. Effect of breakfast skipping on young females menstruation. Health Science Journal 2014; 8 . 
3. Fujiwara T. Diet during adolescence is a trigger for subsequent development of dysmenorrhea in young women. Int J Food Sci Nutr 2007; 58: 437-44.

4. Fujiwara T. Skipping breakfast is associated with dysmenorrhea in young women in Japan. 2003; 54 : 505-09.

5. Fujiwara T, Nakata R. Skipping breakfast is associated with reproductive dysfunction in post-adolescent female college students. J. Appet 2010; 55(3):714-17

6. Schweiger $U$, Tuschl R, Platte $P$ et al. Everyday eating behavior and menstrual function in young women. Fertil Steril 1992; 57(4): 771-75.

7. Bendich A. The potential for dietary supplements to reduce premenstrual syndrome (PMS) symptoms. J
Am Coll Nutr 2000; 19: 3-12.

8. Fujiwara T, Sato N, Awaji H et al. Skipping breakfast adversely affects menstrual disorders in young college students. Int J food Sci Nutr 2009; 60(6): 23-31.

9. Vyver E, Steinegger C, Katzman D. Eating disorders and menstrual dysfunction in adolescents. Ann $N$ Y Acad Sci 2008; 1135: 253-64.

10. Dars S, Sayed K, Yousufzai Z. Relationship of menstrual irregularities to $\mathrm{BMI}$ and nutritional status in adolescent girls. Pak J Med Sci 2014; 30: 140-14.

Date of Submission: 2017-09-28 Date of Acceptance: 2017-10-03 